\title{
ANALISIS DESKRIPTIF BUDAYA ORGANISASI DI LINGKUNGAN DOSEN TETAP PTS SWASTA WILAYAH SUMATERA SELATAN
}

\author{
Muhammad Helmi \\ STIE Mulia Darma Pratama, Palembang. \\ Email: muhammadhelmi@muliadarmapratama.ac.id
}

\begin{abstract}
The background of this research departs from the phenomenon of the demands of the times, which require the world of higher education to produce superior and competitive human resources in the economic field. This condition cannot be fulfilled solely by relying on State Universities. Therefore, the role of private universities is crucial. One of the private universities that can meet this need in the College of Economics. This higher education path is expected to meet the demands for reliable human resources in the economic field, both in the academic world and in the practical world. This condition cannot separate from the role of lecturers in meeting these demands. This study aimed to determine the organizational culture of permanent lecturers in the South Sumatra region. The population in this study were private university lecturers in the South Sumatra region. The research method uses a descriptive survey using descriptive analysis. The number of research samples was 185 respondents/permanent lecturers. The study results illustrate that organizational culture is not good, with two indicators having the lowest value. The indicators in question are doing work carefully and doing work carefully. For this reason, it is necessary to improve indicators by doing work carefully and doing work carefully.
\end{abstract}

Keywords: organizational culture, lecturers.

\begin{abstract}
Abstrak
Latar belakang penelitian ini berangkat dari fenomena tuntutan zaman yang menghendaki agar dunia pendidikan tinggi menghasilkan sumber daya manusia yang unggul dan kompetitif dalam bidang ekonomi. Hal ini tidak bisa dipenuhi hanya dengan mengandalkan Perguruan Tinggi Negeri. Oleh karena itu peran
\end{abstract}


Perguruan Tinggi Swasta (PTS) sangatlah penting. Salah satu PTS yang dapat memenuhi kebutuhan ini adalah Sekolah Tinggi Ilmu Ekonomi. Jalur pendidikan tinggi ini diharapkan dapat memenuhi tuntutan akan SDM yang handal di bidang ekonomi, baik dalam dunia akademis maupun dalam dunia praktis. Hal ini tidak bisa terlepas dari peran dosen dalam memenuhi tuntutan tersebut. Tujuan penelitian ini adalah untuk mengetahui gambaran budaya organisasi pada dosen tetap PTS di wilayah Sumatera Selatan. Populasi dalam penelitian ini adalah dosen tetap PTS di wilayah Sumatera Selatan. Metode penelitian menggunakan descriptive survey dengan menggunakan analisis deskriptif. Jumlah sample penelitian sebanyak 185 responden/dosen tetap. Hasil penelitian menggambarkan budaya organisasi kurang baik menuju baik dimana terdapat 2 indikator yang memiliki nilai terendah. Indikator yang dimaksud yaitu melakukan pekerjaan dengan cermat dan mengerjakan pekerjaan dengan teliti. Untuk itu perlu kiranya untuk meningkatkan indicator dengan cara melakukan pekerjaan dengan cermat dan melakukan pekerjaan dengan teliti.

\section{Kata Kunci: budaya organisasi, dosen tetap.}

\section{PENDAHULUAN}

Tantangan utama bangsa Indonesia ini adalah mempersiapkan individu-individu yang ada menjadi sumber daya manusia yang tangguh dan berkualitas, bukan hanya untuk menghadapi kondisi saat ini namun jauh ke depan mampu menghadapi tantangan yang muncul di masa mendatang. Dalam konteks ini, dunia pendidikan sangat memegang peranan penting dalam usaha menciptakan sumber daya manusia yang unggul, tangguh, dan siap berkompetisi dalam kondisi apapun. Pendidikan merupakan ujung tombak kemajuan suatu bangsa. Negara-negara maju seperti Amerika, Jerman, Inggris, Jepang, China, dan negara maju lainnya menjadikan pendidikan sebagai faktor strategis dalam menciptakan kemajuan bangsanya, sehingga negara-negara maju ini dapat berkompetisi dengan baik.

Dunia pendidikan dalam konteks ini mempunyai beberapa aspek penting dalam dunia pendidikan berkewajiban menyediakan lulusan, bukan saja dalam jumlah besar dan banyak tetapi juga berkualitas dan mempunyai disiplin yang tinggi serta mampu menjadi dinamisator, inovator, motivator dan penggerak perubahan. (Cortese \& Hattan, 2010) Dunia pendidikan berkewajiban menyediakan tenagatenaga terdidik bukan saja yang ahli dan terampil dalam melaksanakan tugas, tetapi juga mampu mengembangkan kemampuan tenaga kerja lainnya. (Brundiers \& Wiek, 2011; Buckley \& Michel, 2020) 
Peningkatan kinerja dosen harus dilakukan Perguruan Tinggi untuk mewujudkan tujuan Pendidikan Nasional sebagaimana yang dikemukakan pada UndangUndang Sisdiknas Nomor 20 Tahun 2003: "Pendidikan Nasional berfungsi mengembangkan kemampuan dan membentuk watak serta peradaban bangsa yang bermartabat dalam rangka mencerdaskan kehidupan bangsa, bertujuan untuk berkembangnya potensi peserta didik aga menjadi manusia yang beriman dan bertakwa kepada Tuhan Yang Maha Esa, berakhlak mulia, sehat, berilmu, cakap, kreatif, mandiri dan menjadi warga negara yang demokratis serta bertanggung jawab. Untuk mewujudkan hal tersebut maka perguruan tinggi harus menerapkan kebijakan kepada setiap dosennya untuk melaksanakan Tri Dharma Perguruan Tinggi. Tri Dharma Perguruan Tinggi mengharuskan seorang dosen untuk melaksanakan kegiatan pendidikan dan pengajaran, penelitian, serta pengabdian kepada masyarakat.

Bidang pendidikan dan pengajaran dimaksud untuk menghasilkan manusia terdidik yang memiliki pengetahuan, kemampuan dan sikap, yang artinya melalui kegiatan pendidikan dan pengajaran diharapkan dapat melahirkan lulusan atau sarjana yang berilmu, berakhlak mulia dan memiliki keterampilan. Untuk itu di dalam kegiatan pembelajaran, seorang dosen dituntut menguasai berbagai kemampuan teknis dan non teknis mulai dari merancang, melaksanakan sampai mengevaluasi kegiatan belajar mengajar. (Kruse, Rakha \& Calderone, 2018)

Pada bidang penelitian, Perguruan Tinggi diharapkan dapat melahirkan teori, konsep dan metodologi serta model dan informasi baru yang dapat memperkaya khasanah ilmu pengetahuan, teknologi dan budaya. Untuk itu dosen diharapkan mampu melahirkan ide-ide, konsep dan gagasan yang dituangkan baik melalui kegiatan penelitian, pembuatan buku ajar, menulis artikel maupun karya-karya ilmiah lainnya. (Buckley \& Michel, 2020) Lahirnya berbagai macam karya penelitian dan karya-karya tulis lainnya merupakan indikator dari dosen yang berkualitas serta memiliki kinerja yang tinggi. Dalam bidang pengabdian kepada masyarakat diharapkan keberadaan lembaga pendidikan tinggi dapat memberikan sumbangan pemikiran dan tenaga kepada masyarakat guna mencapai kemajuan bangsa.

Optimalisasi proses dan aspek manajemen sumber daya manusia dosen memiliki posisi yang penting dalam membentuk mutu lulusan maupun mutu lembaga secara umum. Posisi itu diperkuat dengan fakta bahwa dosen memiliki otoritas tinggi dalam proses akademik sebagaimana dinyatakan dalam Undang-Undang Guru dan Dosen Nomor 14 Tahun 2005, bahwa dosen adalah pendidik profesional dan ilmuwan dengan tugas utama mentransformasikan, mengembangkan, dan menyebarluaskan ilmu pengetahuan, teknologi, dan seni melalui pendidikan, penelitian, dan pengabdian kepada masyarakat. Hal ini diperkuat dengan Undang- 
Undang Republik Indonesia Nomor 12 Tahun 2012 yang menyatakan bahwa yang dimaksud dengan "Dosen yang memiliki otoritas dan wibawa ilmiah untuk menyatakan secara terbuka dan bertanggung jawab mengenai sesuatu yang berkenaan dengan rumpun ilmu dan cabang ilmunya" adalah Dosen yang telah memiliki kualifikasi doktor atau setara.

Salah satu variabel untuk menganalisis keberhasilan perguruan tinggi adalah budaya organisasi, menurut Robbins dan Coulter (2016) budaya organisasi dapat dilihat dari nilai-nilai, prinsip-prinsip, tradisi dan cara-cara bekerja yang dianut bersama oleh para anggota organisasi dan mempengaruhi cara mereka bertindak. Dalam kebanyakan organisasi, nilai-nilai dan praktik-praktik yang dianut bersama ini telah berkembang pesat seiring dengan perkembangan zaman dan benar-benar sangat mempengaruhi bagaimana sebuah organisasi dijalankan, dan Gibson, Ivancevich dan Donelly (2011) sependapat, "Bahwa sebuah organisasi mampu beroperasi secara efisien hanya ketika ada nilai yang diyakini di antara karyawan. Nilai merupakan keinginan efektif, kesadaran, atau keinginan yang membimbing perilaku."

Menurut Dessler (2015) budaya organisasi merupakan karakteristik nilai, tradisi, dan perilaku perusahaan yang dipunyai oleh karyawan. Berdasarkan data prasurvey Budaya Organisasi PTS di wilayah Propinsi Sumatera Selatan pada 50 responden diketahui bahwa nilai rata-rata skor 3,19 yang berada pada kategori jawaban 'Cukup Baik'. Adapun dimensi yang terendah adalah Inovasi dan perhatian terhadap detail, hal ini dapat dipahami bahwa umumnya inovasi yang dimilki oleh para dosen belum optimal disebabkan oleh kurangnya motivasi dari organisasi untuk mendorong agar kreatifitas para dosen dan perhatian terhadap detail lebih meningkat. Faktor lain juga bisa disebabkan karena kurangnya tantangan untuk berkompetisi, baik sesama dosen maupun antar perguruan tinggi.

Menurut Kreitner dan Kinicki (2014:67) menjelaskan bahwa terdapat Empat Fungsi Budaya Organisasi yaitu memberikan para anggota sebuah identitas organisasi, memfasilitasi komitmen bersama, mempromosikan stabilitas system social dan membentuk perilaku dengan membentuk para anggota. Sedangkan Robbins dan Judge (2015) menjelaskan bahwa Budaya Organisasi memiliki fungsi berperan sebagai penentu batas-batas, artinya kultur menciptakan perbedaan atau distingsi antara satu organisasi dengan organisasi lainnya. Hal ini memuat rasa identitas anggota organisasi. Kultur memfasilitasi lahirnya komitmen terhadap sesuatu yang lebih besar daripada kepentingan individu. Kultur meningkatkan stabilitas sistem sosial, kultur adalah perekat sosial yang membantu menyatukan organisasi dengan cara menyediakan standar mengenai apa yang sebaiknya dikatakan dan dilakukan karyawan. Kultur bertindak sebagai 
mekanisme sense-making serta kendali yang menuntun dan membentuk sikap dan perilaku karyawan.

Dengan demikian budaya organisasi memiliki fungsi yang sangat penting dalam rangka memandu perilaku inidividu dan perilakuk kelompok dalam melaksanakan aktivitasya sehingga tercapai tujuan organisasi. Berdasarkan fenomena ini, penulis tertarik untuk melakukan penelitian untuk mengetahui gambaran budaya organisasi dosen tetap pada PTS Wilayah Sumatera Selatan.

Alasan pemilihan lokus PTS di Wilayah Propinsi Sumatera Selatan adalah karena pada umumnya daya saing PTS, tuntutan kompetensi, dan kualitas lulusan PTS di wilayah ini belum optimal bila dibandingkan dengan PTS dan lulusan PTS yang berada di Pulau Jawa, padahal wilayah ini memiliki potensi sumber daya yang unggul, baik sumber daya manusia maupun sumber daya lainnya. Alasan yang tak kalah pentingnya adalah dalam rangka menindaklanjuti program pemerintah yang berkaitan dengan pemerataan pembangunan di Indonesia, khususnya dalam konteks ini adalah pembangunan di bidang pendidikan, lebih spesifik lagi pembangunan sumber daya manusia di bidang pendidikan.

Lebih dalam lagi, alasan pemilihan Sekolah Tinggi Ilmu Ekonomi atau STIE Swasta yang dipilih sebagai lokus penelitian adalah karena kebutuhan lapangan pekerjaan yang dibutuhkan di Sumatera Selatan dominan berasal dari jurusan manajemen dan akuntansi, dimana jurusan atau program studi ini merupakan rumpun ilmu ekonomi. Harapan masyarakat luas tentunya menginginkan agar selain perguruan tinggi negeri yang ada, perguruan tinggi swasta dapat menghasilkan kualitas lulusan sarjana, khususnya sarjana lulusan manajemen maupun lulusan akuntansi yang memiliki kualitas, kompetensi, dan daya saing yang tinggi. Untuk memenuhi tuntutan tersebut, tentunya tidak bisa terlepas dari kualitas, kompetensi, dan daya saing dosen yang terlibat di dalamnya. Oleh sebab itu, penulis tertarik untuk memilih Sekolah Tinggi Ilmu Ekonomi Swasta di Sumatera Selatan sebagai lokus dalam penelitian ini, dengan harapan hasil penelitian ini dapat memberikan kontribusi baik secara akademik maun secara praktis.

\section{METODE PENELITIAN}

Metode Penelitian yang digunakan adalah metode penelitian survey dengan pendekatan studi deskriptif dimana peneliti melakukan survey terhadap objek penelitian dengan maksud untuk mengetahui gambaran dengan mengacu pada landasan teori yang digunakan. Penelitian ini merupakan katagori penelitian populasi, yaitu informasi dari seluruh responden dikumpulkan langsung dari 
lokasi dengan tujuan untuk mengetahui pendapat seluruh populasi terhadap objek yang diteliti. Penelitian ini dilakukan selama 6 bulan pada tahun 2020 .

Desain penelitian ini dibuat untuk mengetahui latar belakang permasalahan yang sedang dihadapi, konsep dasar pemikiran yang dijadikan acuan, pendekatanpendekatan yang digunakan, teknik pengambilan atau pengumpulan data yang dipakai dan analisis data. Desain penelitian merupakan seluruh proses yang diperlukan dalam perencanaan dan pelaksanaan penelitian. Adapun prosesnya dimanan peneliti terlebih dahulu melakukan identifikasi dan pemilihan masalah penelitian, kemudian melakukan pemilihan kerangka konseptual untuk masalah penelitian serta hubungannya dengan penelitian sebelumnya. Memformulasikan masalah penelitian termasuk membuat spesifikasi dan tujuan penelitian. Memilih serta memberi definisi terhadap pengukuran variabel-variabel. Memilih prosedur dan teknik sampling yang digunakan serta melakukan membuat coding dan mengadakan editing serta processing data serta menganalisis data sesuai dengan hasil rekapitulasi data yang telah dilakukan sebelumnnya.

Berdasarkan rumusan masalah yang diajukan, maka variabel yang digunakan dalam penelitian ini adalah Variabel Budaya Organisasi. Budaya organisasi adalah seperangkat asumsi, keyakinan, nilai-nilai, dan norma-norma yang dianut oleh anggota organisasi (Robbins dan Coulter, 2012:52). Adapun Dimensi Budaya Organisasi terdiri dari Inovasi, Perhatian terhadap detail, Berorientasi pada hasil, Berorientasi pada manusia, Berorientasi pada tim, Agresif dan Stabil.

Sumber data dalam penelitian ini terdiri dari data Data primer, yaitu data yang digunakan dalam penelitian ini adalah data yang diperoleh langsung dari responden, dalam hal ini dosen tetap di wilayah Sumatera Selatan yang meliputi jawaban kusioner dan wawancara. Data sekunder, yaitu data diperoleh melalui pihak lain yang berkepentingan dan berkaitan dalam penelitian ini. Data sekunder antara lain data jumlah STIE Swasta dan jumlah dosen tetap STIE Swasta.

Metode pengumpulan data yang digunakan dalam penelitian ini dilakukan dengan mengunpulkan kuesioner, yaitu teknik pengumpulan data yang dilakukan dengan jalan menyebarkan pertanyaan-pertanyaan kepada responden. Populasi dalam penelitian ini adalah dosen tetap STIE Swasta di wilayah Sumatera Selatan. Adapun sample responden berjumlah 185 orang dosen tetap, pengambilan sample dengan menggunakan teknik simple random, dimana peneliti melakukan survey terhadap STIE Swasta di wilayah Sumatra Selatan secara acak.

Langkah selanjutnya yang harus dilakukan setelah terkumpulnya data dari seluruh responden yaitu mengelompokan data berdasarkan variabel dan jenis responden, mentabulasi data berdasarkan variabel dari seluruh responden, menyajikan data 
dari variabel yang diteliti dan melakukan perhitungan untuk menjawab rumusan masalah. Dalam menginterpretasikan dan menganalisis data, digunakan analisis deskriptif. Analisis deskriptif ditujukan untuk menggambarkan karakteristik responden dan variabel dari penelitian yang dilaksanakan.

\section{HASIL DAN PEMBAHASAN}

Pada prinsipnya analisis deskriptif digunakan untuk mengubah kumpulan data menjadi bentuk yang informatif yang mudah dipahami. Hal ini penting, karena pada level pengguna maupun level manajerial dalam suatu organisasi atau perusahaan butuh informasi yang mudah untuk dipahami. Dalam analisis deskriptif nilai bisa diwakili oleh mean, median, modus, frekuensi, persentase dan bentuk diagram lainnya. Pada penelitian ini, analisis deskriptif dimaksudkan untuk mendapatkan gambaran/deskripsi mengenai tanggapan dari dosen mengenai budaya dosen tetap Sekolah Tinggi Ilmu Ekonomi Swasta di Wilayah Sumatera Selatan.

Hasil rekapitulasi analisis deskriptif untuk variabel budaya organisasi berdasarkan dimensinya dapat dilihat pada tabel berikut:

Tabel 1. Rekapitulasi Dimensi Variabel Budaya Organisasi

\begin{tabular}{|c|l|c|c|}
\hline No & \multicolumn{1}{|c|}{ Dimensi } & Rata-rata & Standar Deviasi \\
\hline 1 & Inovasi & 3.102 & 0,785 \\
\hline 2 & Perhatian Terhadap Detail & 2.900 & 0,935 \\
\hline 3 & Berorientasi Pada Hasil & 3.825 & 0,691 \\
\hline 4 & Berorientasi pada Manusia & 3.393 & 0,926 \\
\hline 5 & Berorientasi pada Tim & 3.733 & 0,822 \\
\hline 6 & Agresif & 3.471 & 0,763 \\
\hline 7 & Stabil & 3.675 & 0,848 \\
\hline \multicolumn{2}{|c|}{ Rata-rata } & 3,371 & 0,826 \\
\hline \multicolumn{2}{|c|}{ Rentang Nilai } & Kurang Kuat (Lemah) s.d Kuat \\
\hline \multicolumn{2}{|c|}{ Kategori } & \multicolumn{2}{c|}{ s.d 4,197 } \\
\hline
\end{tabular}

Berdasarkan pada tabel tersebut terlihat bahwa secara rata-rata responden memiliki persepsi sebesar 3,371 dengan standar deviasi sebesar 0,826, sehingga rentang nilai yang diperoleh berada pada rentang 2,545 sampai dengan 4,197 yang dapat dikategorikan pada rentang kurang kuat (lemah) sampai dengan kuat. Hal tersebut berarti bahwa variabel yang diukur masih belum optimal dan harus lebih ditingkatkan. 
Guna mengetahui lebih detail mengenai hasil deskriptif variabel tersebut, dapat diuraikan berdasarkan seluruh indikator pembentuknya melalui pernyataanpernyataan berikut:

Tabel 2. Rekapitulasi Indikator Variabel Budaya Organisasi

\begin{tabular}{|c|c|c|c|c|c|c|c|c|c|}
\hline \multicolumn{10}{|c|}{ Variabel Budaya Organisasi } \\
\hline \multirow{2}{*}{$\begin{array}{l}\mathbf{N} \\
\mathbf{0}\end{array}$} & \multirow[t]{2}{*}{ Pertanyaan } & \multicolumn{5}{|c|}{ Skor Penilaian } & \multirow{2}{*}{$\begin{array}{c}\text { Rata- } \\
\text { rata }\end{array}$} & \multirow{2}{*}{$\begin{array}{l}\text { Stand } \\
\text { ar } \\
\text { Devias } \\
\text { i }\end{array}$} & \multirow{2}{*}{$\begin{array}{c}\text { Katego } \\
\text { ri }\end{array}$} \\
\hline & & 5 & 4 & 3 & 2 & 1 & & & \\
\hline \multicolumn{10}{|c|}{ Inovasi } \\
\hline 1 & $\begin{array}{l}\text { Melakukan } \\
\text { inovasi pada } \\
\text { setiap } \\
\text { aktivitas Tri } \\
\text { Dharma PT }\end{array}$ & 4 & 33 & 53 & 11 & 2 & 3.25 & .776 & $\mathrm{CB}$ \\
\hline 2 & $\begin{array}{l}\text { Mengambil } \\
\text { risiko yang } \\
\text { terukur } \\
\text { dalam setiap } \\
\text { aktivitas } \\
\text { yang } \\
\text { menjadi } \\
\text { tugas saya }\end{array}$ & 3 & 31 & 53 & 14 & 2 & 3.18 & .776 & $\mathrm{CB}$ \\
\hline 3 & $\begin{array}{l}\text { Melakukan } \\
\text { aktivitas } \\
\text { dengan } \\
\text { penuh } \\
\text { inisiatif }\end{array}$ & 3 & 21 & 57 & 17 & 5 & 3.00 & .828 & $\mathrm{CB}$ \\
\hline 4 & $\begin{array}{l}\text { Melakukan } \\
\text { kreativitas } \\
\text { pada setiap } \\
\text { aktivitas Tri } \\
\text { Dharma PT }\end{array}$ & 0 & 26 & 50 & 25 & 2 & 2.97 & .760 & $\mathrm{CB}$ \\
\hline & Total & 10 & 111 & 213 & 15 & 11 & 3.102 & 0.785 & $\mathrm{CB}$ \\
\hline \multicolumn{10}{|c|}{ Perhatian Terhadap Detail } \\
\hline 5 & $\begin{array}{l}\text { Melakukan } \\
\text { pekerjaan } \\
\text { dengan } \\
\text { cermat }\end{array}$ & 5 & 23 & 44 & 21 & 10 & 2.92 & 1.007 & $\mathrm{CB}$ \\
\hline 6 & $\begin{array}{l}\text { Melakukan } \\
\text { pekerjaan } \\
\text { dengan } \\
\text { detail }\end{array}$ & 4 & 24 & 45 & 26 & 4 & 2.98 & .896 & $\mathrm{CB}$ \\
\hline 7 & $\begin{array}{l}\text { Melakukan } \\
\text { pekerjaan } \\
\text { dengan teliti }\end{array}$ & 1 & 21 & 46 & 26 & 9 & 2.80 & .901 & $\mathrm{CB}$ \\
\hline & Total & 10 & 68 & 135 & 73 & 23 & 2.900 & 0.935 & $\mathrm{CB}$ \\
\hline \multicolumn{10}{|c|}{ Berorientasi Pada Hasil } \\
\hline 8 & $\begin{array}{l}\text { Memperhati } \\
\text { kan target }\end{array}$ & 17 & 53 & 31 & 2 & 0 & 3.83 & .720 & $\mathrm{~B}$ \\
\hline
\end{tabular}


Helmi, Analisis Deskriptif Budaya Organisasi

April , 2021

\begin{tabular}{|c|c|c|c|c|c|c|c|c|c|}
\hline & capaian & & & & & & & & \\
\hline 9 & $\begin{array}{l}\text { Berorientasi } \\
\text { pada hasil } \\
\text { kerja }\end{array}$ & 14 & 58 & 30 & 1 & 0 & 3.83 & .663 & B \\
\hline & Total & 31 & 111 & 61 & 3 & 0 & 3.825 & 0.691 & B \\
\hline \multicolumn{10}{|c|}{ Berorientasi Pada Manusia } \\
\hline 10 & $\begin{array}{l}\text { Berorientasi } \\
\text { pada } \\
\text { mahasiswa } \\
\text { dalam } \\
\text { mengambil } \\
\text { keputusan }\end{array}$ & 8 & 53 & 15 & 27 & 0 & 3.41 & .964 & B \\
\hline 11 & $\begin{array}{l}\text { Membuat } \\
\text { keputusan } \\
\text { manajemen }\end{array}$ & 9 & 38 & 41 & 13 & 2 & 3.38 & .887 & $\mathrm{CB}$ \\
\hline & Total & 17 & 91 & 56 & 40 & 2 & 3.393 & 0.926 & $\mathrm{CB}$ \\
\hline \multicolumn{10}{|c|}{ Berorientasi Pada Tim } \\
\hline 12 & $\begin{array}{l}\text { Berperilaku } \\
\text { untuk } \\
\text { bekerjasama } \\
\text { dalam tim } \\
\text { untuk } \\
\text { mencapai } \\
\text { tujuan } \\
\end{array}$ & 21 & 45 & 29 & 8 & 0 & 3.77 & .866 & $\mathrm{~B}$ \\
\hline 13 & $\begin{array}{l}\text { Berperilaku } \\
\text { untuk maju }\end{array}$ & 12 & 56 & 27 & 8 & 0 & 3.70 & .778 & B \\
\hline & Total & 33 & 101 & 56 & 16 & 0 & 3.733 & 0.822 & B \\
\hline \multicolumn{10}{|c|}{ Agresif } \\
\hline 14 & $\begin{array}{l}\text { Bersikap } \\
\text { kompetitif }\end{array}$ & 8 & 37 & 48 & 10 & 0 & 3.42 & .774 & B \\
\hline 15 & $\begin{array}{l}\text { Bersikap } \\
\text { agresif }\end{array}$ & 9 & 43 & 44 & 7 & 0 & 3.52 & .752 & B \\
\hline & Total & 17 & 80 & 92 & 17 & 0 & 3.471 & 0.763 & $\mathrm{~B}$ \\
\hline \multicolumn{10}{|c|}{ Stabil } \\
\hline 16 & $\begin{array}{l}\text { Menjaga } \\
\text { kestabilan } \\
\text { dalam } \\
\text { organisasi }\end{array}$ & 18 & 48 & 29 & 7 & 1 & 3.73 & .865 & B \\
\hline 17 & $\begin{array}{l}\text { Menolak } \\
\text { status quo } \\
\text { dalam } \\
\text { organisasi }\end{array}$ & 18 & 33 & 47 & 5 & 0 & 3.62 & .830 & B \\
\hline & Total & 36 & 81 & 76 & 12 & 1 & 3.675 & 0.848 & $\mathrm{~B}$ \\
\hline \multicolumn{2}{|c|}{ Jumlah Skor } & 154 & 451 & 552 & 161 & 36 & & & \\
\hline \multicolumn{2}{|c|}{ Total Bobot } & 770 & 1804 & 1656 & 322 & 36 & 4588 & & \\
\hline \multicolumn{2}{|c|}{ Persentase } & $\begin{array}{r}16.78 \\
\%\end{array}$ & $\begin{array}{r}39.32 \\
\%\end{array}$ & $\begin{array}{r}36.09 \\
\%\end{array}$ & $\begin{array}{r}7.02 \\
\% \\
\end{array}$ & $\begin{array}{r}0.78 \\
\%\end{array}$ & $\begin{array}{r}100.00 \\
\%\end{array}$ & & \\
\hline \multicolumn{2}{|c|}{ Rata-rata } & \multicolumn{8}{|r|}{3.371} \\
\hline \multicolumn{2}{|c|}{ Stadar Deviasi } & \multicolumn{8}{|r|}{0.826} \\
\hline \multirow{2}{*}{\multicolumn{2}{|c|}{$\begin{array}{l}\text { Rentang Nilai } \\
\text { Kategori }\end{array}$}} & 2.54 & s.d & 4.20 & & & & & \\
\hline & & $\mathbf{K B}$ & S.d & B & & & & & \\
\hline
\end{tabular}

Bisnis Dan Iptek | Sekolah Tinggi Ilmu Ekonomi Pasundan Bandung 
Variabel Budaya Organisasi dalam penelitian ini memiliki 2 indikator dengan skor penilaian tertinggi yaitu pada indikator memperhatikan target capaian (X1.8) dengan skor penilaian sebesar 3,83 dan pada indikator berorientasi pada hasil (X1.9) dengan skor penilaian yang juga sebesar 3,83. Dari sudut pandang indikator dengan skor penilaian tertinggi yaitu pada indikator memperhatikan target capaian telah menunjukkan bahwa budaya organisasi pada STIE di Sumatera Selatan telah dapat memacu dosen tetap yang telah tersertifikasi dapat berkerja dengan berfokus pada target capaian yang telah ditetapkan. Hal tersebut penting dikarenakan target capaian merupakan blueprint rancangan kerja suatu perguruan tinggi, sebagai gambaran dan rancangan kinerja yang harus dicapai dalam periode waktu tertentu.

Selanjutnya berkaitan dengan indikator dengan penilaian tertinggi lainnya yaitu pada indikator berorientasi pada hasil kerja, penilaian yang tinggi pada indikator tersebut juga merupakan indikasi bahwa budaya organisasi pada STIE di Sumatera Selatan telah dapat mendorong para dosen tetap yang telah tersertifikasi memiliki motivasi untuk berorientasi pada capaian hasil kerja sesuai dengan target yang telah ditetapkan. Hasil tersebut dapat dinyatakan kuat berdasarkan skor penilaian indikator penelitian, mengingat salah satu dimensi budaya organisasi yang baik merupakan budaya organisasi yang memiliki orientasi terhadap hasil kerja yang optimal. Kedua penilaian tertinggi pada skala indikator tersebut juga membuat dimensi berorientasi terhadap hasil menjadi dimensi dengan skor penilaian tertinggi, yaitu sebesar 3,825 .

Kemudian selain indikator tertinggi juga terdapat indikator dengan skor penilaian terendah yaitu pada indikator melakukan pekerjaan dengan cermat (X1.5) dengan skor penilaian sebesar 2,92 dan pada indikator melakukan pekerjaan dengan teliti (X1.7) dengan skor penilaian sebesar 2,80. Dari sudut pandang indikator dengan penilaian terendah yaitu pada indikator melakukan pekerjaan dengan cermat dan melakukan pekerjaan dengan teliti, hasil penilaian dalam penelitian ini menunjukkan bahwa budaya organisasi pada STIE di Sumatera Selatan belum dapat mendorong para dosen tetap yang telah tersertifikasi untuk dapat bekerja dengan cermat dan teliti.

Bekerja dengan cermat yang dimaksud adalah bekerja dengan seksama dan penuh perhatian sedangkan bekerja dengan teliti yang dimaksud dalam penelitian ini adalah bekerja dengan tingkat kesalahan yang minimal. Masih belum optimalnya tingkat kecermatan dan ketelitian para dosen STIE di Sumatera Selatan tersebut berdasarkan penelitian yang dilakukan disebabkan oleh cukup rumitnya pekerjaan yang dilakukan oleh para dosen terutama menyangkut pekerjaan dalam ranah administratif yang menjadi bagian dari tanggung jawab profesi. Selain itu masih adanya aturan yang dirasa cukup membingungkan bagi para dosen. Kerumitan tersebut menjadi awal dari rendahnya kecermatan dan ketelitian terhadap 
pekerjaan yang dilakukan. Oleh karena itu perlu dilakukan perbaikan pada beberapa hal tersebut sebagai upaya meningkatkan dorongan organisasi terhadap para dosen untuk bekerja secara lebih cermat dan teliti.

Selanjutnya kedua indikator tersebut berperan dominan menghasilkan dimensi perhatian terhadap detail sebagai dimensi pada variabel budaya organisasi dengan skor penilaian terendah yaitu sebesar 2,900. Mengacu pada hasil pengolahan data dan analisis hasil penelitian yang dilakukan, dapat diperoleh gambaran mengenai variabel Budaya Organisasi yaitu dengan nilai rata-rata 3,371 dan standar deviasi 0,826. Skor tersebut dalam kriteria penafsiran termasuk kategori cukup baik. Hal ini menunjukkan bahwa Budaya Organisasi di STIE Swasta Wilayah Propinsi Sumatera Selatan cukup kuat (sedang). Dengan demikian, budaya organisasi ini masih perlu ditingatkan.

Faktor terbesar yang mendominasi nilai variabel Budaya Organisasi ini adalah indikator Memperhatikan Target Capaian (X1.8) dan indikator Berorientasi pada Hasil Kerja (X1.9) dengan nilai masing-masing 3,83, keduanya masuk dalam kategori kuat. Sehingga faktor memperhatikan target capaian dan berorientasi pada hasil kerja merupakan keunggulan dari Budaya Organisasi di STIE Swasta Wilayah Propinsi Sumatera Selatan. Memperhatikan target capaian dan berorientasi pada hasil kerja merupakan faktor penyumbang nilai terbesar atau faktor utama pembentuk Budaya Organisasi di STIE Swasta Wilayah Propinsi Sumatera Selatan. Oleh sebab itu kedua faktor ini menjadi prioritas utama dalam usaha meningkatkan nilai variabel Budaya Organisasi di STIE Swasta Wilayah Propinsi Sumatera Selatan. Namun jika sudah sangat sulit untuk meningkatkan nilai item-item tersebut, maka setidaknya dengan cara mempertahankan agar jangan sampai nilai item tersebut turun.

Selanjutnya adalah pembahasan masalah dari sisi kelemahan atau kekurangan, yaitu faktor-faktor yang dianggap memperlemah nilai Budaya Organisasi. Sedikitnya ada dua faktor dengan nilai terendah, yaitu indikator Melakukan Pekerjaan dengan Cermat (X1.5) memiliki skor 2,92 atau berada pada kategori cukup kuat dan indikator Melakukan Pekerjaan dengan Teliti (X1.7) memiliki skor 2,80 atau berada pada kategori cukup kuat. Hal ini mengandung makna bahwa faktor Melakukan Pekerjaan dengan Cermat dan Melakukan Pekerjaan dengan Teliti merupakan kelemahan dari Budaya Organisasi di STIE Swasta Wilayah Propinsi Sumatera Selatan.

Kedua faktor kelemahan atau kekurangan ini antara lain disebabkan karena regulasi pemerintah yang sangat dinamis, SOP masih bersifat umum (general) sehingga menimbulkan banyak multitafsir, deskripsi pekerjaan atau job description yang belum spesifik, serta kompetensi sumber daya manusia yang belum optimal. Karena kedua faktor ini memiliki nilai yang paling rendah, maka 
peningkatan kedua hal tersebut menjadi prioritas dalam usaha peningkatkan kondisi Budaya Organisasi di STIE Swasta Wilayah Propinsi Sumatera Selatan. Alternatif solusi (strategi) untuk meningkatakan unsur atau indikator melakukan pekerjaan dengan cermat dan melakukan pekerjaan dengan Teliti diantaranya adalah dengan cara berikut.

Berkaitan dengan regulasi pemerintah yang sangat dinamis, maka pihak kampus, dalam hal ini diwakili oleh pengambil kebijakan di perguruan tinggi yang bersangkutan memberikan usulan atau masukan kepada pihak terkait (misal APTISI atau LLDIKTI). (Felipe, Roldán \& Leal-Rodríguez, 2017) Sedangkan terkait permasalahan SOP yang masih bersifat umum (general), maka pihak manajemen perguruan tinggi dibantu dosen terkait untuk membuat SOP yang lebih jelas atau spesifik, sehingga diperoleh pemahaman yang sama (tidak ada multi tafsir). (Warrick, 2017) Berhubungan dengan masalah job description yang belum spesifik, maka pihak manajemen perguruan tinggi bekerja sama dengan dosen terkait membuat job description yang lebih jelas secara teknis operasional, lebih jelas tentang siapa mengerjakan apa, dan apa yang harus dilakukan secara detail oleh masing-masing personal. (Elsbach \& Stigliani, 2018) Disamping hal tersebut, perlu juga disusun analisis beban kerja yang terukur. (Hardiyana, Yusup \& Sidharta, 2015; McFadden, Mallett \& Leiter, 2018; Christy \& Priartini, 2019)

Selanjutnya berkaitan dengan permasalahan kompetensi sumber daya manusia yang belum optimal, maka pihak pengambil kebijakan dan manajemen perguruan tinggi hendaknya mengadakan pelatihan secara berkala yang diperuntukkan untuk meningkatkan kompetensi para dosen yang ada. (Syaifuddin \& Sidharta, 2017; Selvanathan, Yan, Supramaniam, Arumugam \& Suppramaniam, 2019) Pelatihan sebaiknya mendatangkan praktisi atau expert di bidangnya, sehingga para dosen selain memiliki kompetensi secara akademik juga memiliki wawasan tentang pengalaman praktis di lapangan. (Kruse, Rakha \& Calderone, 2018; Khan, Ismail, Hussain \& Alghazali, 2020)

Dari hasil survey berupa penyebaran kuesiner tentang Budaya Organisasi, selanjutnya diperoleh respon dari para Dosen sebagai responden yang menunjukkan bahwa Budaya Organisasi di STIE Swasta Wilayah Propinsi Sumatera Selatan ini secara umum sudah cukup kuat. Secara konseptual, gambaran budaya organisasi di atas sejalan dengan teori / pendapat dari Schein dalam Gibson, Ivancevich dan Donelly (2011) yang mendefinisikan bahwa Budaya Organisasi adalah suatu pola dari asumsi dasar yang diciptakan, ditemukan, atau dikembangkan oleh kelompok tertentu saat belajar menghadapi masalah adaptasi eksternal dan integrasi internal yang telah berjalan cukup baik untuk dianggap valid dan oleh karena itu untuk diajarkan kepada anggota baru sebagai cara yang benar untuk berpersepsi, berpikir dan berperasaan sehubungan dengan masalah yang dihadapinya. Gibson, Ivancevich dan Donelly (2011) yang 
menjelaskan bahwa budaya yang akhirnya berkembang dalam suatu organisasi tertentu adalah suatu hasil kompleks dari tekanan eksternal, potensi internal, respon terhadap peristiwa kritis, dan mungkin faktor kesempatan yang tidak dapat diramalkan dari pengetahuan lingkungan atau dari anggota.

\section{KESIMPULAN}

Dari semua indikator budaya organisasi yang direpresentasikan dalam bentuk pernyataan, terdapat 2 indikator yang memiliki nilai terendah. Indikator yang dimaksud yaitu melakukan pekerjaan dengan cermat dan mengerjakan pekerjaan dengan teliti. Ini mengandung makna bahwa dari perspektif indikator, melakukan pekerjaan dengan cermat dan mengerjakan pekerjaan dengan teliti merupakan kelemahan dari budaya organisasi di STIE Swasta Wilayah Propinsi Sumatera Selatan. Dengan meningkatkan kedua indikator yang telah disebutkan, diharapkan bisa mengungkit atau meningkatkan kondisi budaya organisasi di STIE Swasta Wilayah Propinsi Sumatera Selatan.

Sedikitnya ada dua hal yang harus lebih ditingkatkan lagi agar budaya organisasi ini lebih maksimum (karena adanya unsur indikator yang masih rendah), yaitu melakukan pekerjaan dengan cermat dan melakukan pekerjaan dengan teliti. Untuk meningkatkan indikator melakukan pekerjaan dengan cermat dan melakukan pekerjaan dengan teliti adalah dengan cara melakukan review atau evaluasi secara berkala terhadap SOP, job description, dan kompetensi.

Dengan meningkatnya indikator melakukan pekerjaan dengan cermat dan indikator melakukan pekerjaan dengan teliti diharapkan akan meningkatkan dimensi perhatian terhadap detail yang akan berimplikasi pada peningkatan variabel budaya organisasi. Dengan kata lain, peningkatan faktor melakukan pekerjaan dengan cermat dan faktor melakukan pekerjaan dengan teliti akan meningkatkan perhatian terhadap detail yang akan berimbas pada meningkatnya budaya organisasi di STIE Swasta Wilayah Propinsi Sumatera Selatan.

\section{REFERENSI}

Buckley, J. B., \& Michel, J. O. (2020). An examination of higher education institutional level learning outcomes related to sustainability. Innovative Higher Education, 45(3), 201-217.

Brundiers, K., \& Wiek, A. (2011). Educating students in real-world research: Vision and implementation. Innovative Higher Education, 36, 107-125. 
Christy, M. Y. P., \& Priartini, P. S. (2019). Role of work stress and organizational commitments in educating workload effect on intention to quit. International research journal of management, IT and social sciences, 6(4), 8-16.

Cortese, A. D., \& Hattan, A. S. (2010). Research and solutions: Education for sustainability as the mission of higher education. Sustainability: The Journal of Record, 3, 48-52.

Dessler, G. (2015). Human Resource Management, Fourteenth Edition. England: Pearson Education Limited.

Elsbach, K. D., \& Stigliani, I. (2018). Design thinking and organizational culture: A review and framework for future research. Journal of Management, 44(6), 2274-2306. https://doi.org/10.1177/0149206317744252

Felipe, C. M., Roldán, J. L., \& Leal-Rodríguez, A. L. (2017). Impact of organizational culture values on organizational agility. Sustainability, 9(12), 2354. https://doi.org/10.3390/su9122354

Gibson, J. L., Ivancevich, J. M., Donnelly, Jr, J. H., \& Kanopaske, R. (2011). Organizations: Behavior, Structure, Process, Twelfth Edition. Singapore: McGraw-Hill Education.

Hardiyana, A., Yusup, M., \& Sidharta, I. (2015). Perception of Work and Commitment toward Employee Satisfaction on Non-Ministerial Government Agencies in Bandung Indonesia. Journal of Knowledge Management, Economics and Information Technology, 6(1), 1-15.

Khan, M. A., Ismail, F. B., Hussain, A., \& Alghazali, B. (2020). The interplay of leadership styles, innovative work behavior, organizational culture, and organizational citizenship behavior. Sage Open, 10(1), 2158244019898264. https://doi.org/10.1177/2158244019898264

Kreitner, R., \& Kinicki, A. (2014). Perilaku Organisasi, Edisi 9. Jakarta: Penerbit Salemba Empat.

Kruse, S. D., Rakha, S., \& Calderone, S. (2018). Developing cultural competency in higher education: An agenda for practice. Teaching in Higher Education, 23(6), 733-750. https://doi.org/10.1080/13562517.2017.1414790

McFadden, P., Mallett, J., \& Leiter, M. (2018). Extending the two-process model of burnout in child protection workers: The role of resilience in mediating burnout via organizational factors of control, values, fairness, reward, workload, and community relationships. Stress and Health, 34(1), 72-83. https://doi.org/10.1002/smi.2763 
Robbins, S. P., \& Coulter, M. (2016). Management, Thirteen Edition. England: Pearson Education Limited.

Robbins, S. P., \& Judge, T. A. (2015). Organizational Behavior, Sixteenth Edition. England: Pearson Education Limited.

Selvanathan, M., Yan, D., Supramaniam, M., Arumugam, T., \& Suppramaniam, S. (2019). Lecturers' Productivity in Private Universities, Kazakhstan. Universal Journal of Educational Research,7(12), 25582567.

Syaifuddin, S., \& Sidharta, I. (2017). Desire and climate on employee performance-a study on plantation state-owned enterprise in Indonesia. Problems and Perspectives in Management, 15(4), 222-229. doi:10.21511/ppm.15(4-1).2017.06

Warrick, D. D. (2017). What leaders need to know about organizational culture. Business Horizons, 60(3), 395-404. https://doi.org/10.1016/j.bushor.2017.01.011 